\title{
Questes
}

vestes Revue pluridisciplinaire d'études médiévales

9 | 2006

À la marge

\section{À la marge : éléments bibliographiques}

Julien Abed

\section{(2) OpenEdition}

Journals

Édition électronique

URL : http://journals.openedition.org/questes/2088

DOI : 10.4000/questes.2088

ISSN : 2109-9472

\section{Éditeur}

Les Amis de Questes

\section{Édition imprimée}

Date de publication : 15 juin 2006

Pagination : $67-70$

ISSN : 2102-7188

\section{Référence électronique}

Julien Abed, «À la marge : éléments bibliographiques », Questes [En ligne], 9 | 2006, mis en ligne le 01 janvier 2014, consulté le 15 septembre 2020. URL : http://journals.openedition.org/questes/2088 


\title{
Choix bibliographique
}

\author{
Julien ABED
}

ACCARIE, Maurice, «Poésie, fine amor et amour courtois. La course à la marginalité dans la civilisation féodale ", dans Théâtre, littérature et société au Moyen Âge, Nice, Serre, 2004, pp. 189-221.

AleXANDER, Jonathan James Graham, "Preliminary Marginal Drawings in Medieval Manuscripts", dans Artistes, artisans et production artistique au Moyen Age, 3, Fabrication et consommation de l'œuvre, colloque international organisé par le Centre national de la recherche scientifique, Université de Rennes II-Haute Bretagne, 2-6 mai 1983, éd. Xavier BARRAL I Altet, Paris, Picard, 1990, pp. 307-321.

ArnheIm, Rudolf, The Power of the Center: A Study of Composition in the Visual Arts, Berkeley, University of California Press, 1982.

Aspects de la marginalité au Moyen Âge, Actes du $1^{\text {er }}$ colloque de l'Institut d'études médiévales de l'Université de Montréal, sous la dir. de Guy-H. ALLARD, Montréal, L'Aurore, 1975.

Aussenseiter zwischen Mittelalter und Neuzeit : Festschrift für Hans-Jürgen Goertz zum 60. Geburtstag, hrsg. von Norbert FISCHER und Marion KoBELT-GrOCH, Leiden/New York/Köln, Brill, 1997.

BABCOCK-ABRAHAMS, Barbara, " "A Tolerated Margin of Mess": The Trickster and his Tales Reconsidered », Journal of the Folklore Institute, XI (1975), pp. 147-186.

BALTRUŠAITIS, Jurgis, Formations, déformations, la stylistique ornementale dans la sculpture romane, Paris, Ernest Leroux, 1931.

BALtRUŠAitis, Jurgis, Le Moyen Âge fantastique. Antiquités et exotismes dans l'art gothique, Collection Henri Focillon, Paris, Armand Colin, 1955.

BALtRUŠAITIS, Jurgis, Réveils et prodiges : le Gothique fantastique, Paris, Armand Colin, 1960.

BAQUERO Moreno, Humberto, Exilados, marginais e contestatários na sociedade portuguesa medieval : estudos de história, Lisboa, Editorial Presença, 1990.

BÉRIAC, Françoise, Des lépreux aux cagots : recherches sur les sociétés marginales en Aquitaine médiévale, Bordeaux, Fédération historique du Sud-Ouest, 1990. 
Botto Varela, Gerardo, Molina Figueras, Joan, « Satire et comique dans l'illustration marinale: un manuscrit du gothique international catalan ", Flanders in European Perspective : Manuscript Illumination around 1400 in Flanders and Abroad, proceedings of the international colloquium Leuven, 7-10 september 1993, ed. by Maurits SMEYERS and Bert CARDON, Louvain, 1995, pp. 155-170.

CAMiLle, Michael, Images dans les marges : aux limites de l'art médieval, trad. de l'anglais par Béatrice et Jean-Claude BonNE, Paris, Gallimard, 1997 (coll. Le temps des images) [1 $1^{\text {ère }}$ éd. Image on the Edge: The Margins of Medieval Art, London, Reaktion books, 1992].

Criticism and Dissent in the Middle Ages, ed. by Rita Copeland, Cambridge, Cambridge University Press, 1996.

DuBY, Georges, "A propos de la marginalité dans la société féodale », Revue pratique de psychologie de la vie sociale et d'hygiène mentale, t. 31, 1983, pp. 4-6.

Exclus et systèmes d'exclusion dans la littérature et la civilisation médiévales, Aix-enProvence, éditions CUERMA, Paris, diffusion Honoré Champion, 1978 (coll. Senefiance).

Exile in the Middle Ages, Actes du colloque de Leeds, 8-11 juillet 2002, sous la direction de Laura NAPRAN et Elizabeth M. C. VAN HouTs, Turnhout, Brepols, 2004.

FrITZ, Jean-Marie, Le discours du fou au Moyen Âge, Paris, Presses Universitaires de France, 1992.

GEREMEK, Bronisław, Les Marginaux parisiens aux XIV et XV siècles, trad. du polonais par Daniel BEAUVOIS, Paris, Flammarion, 1990.

GEREMEK, Bronisław, «Le marginal », dans L'Homme médiéval, sous la dir. de Jacques LE Goff, trad. du ms. polonais par Joanna ARNOLD-MorICET, Paris, Éditions du Seuil, 1989, pp. 381-413.

Goodich, Michael, Other Middle Ages: Witnesses at the Margins of Medieval Society, Philadelphia (Penn.), University of Pennsylvania Press, 1998.

GUERRA, Enrica, Una eterna condanna : la figura del carnefice nella società italiana tardomedievale, Milano, F. Angeli, 2003.

Guglielmi, Nilda, Marginalidad en la Edad Media, Buenos Aires, Editorial universitaria de Buenos Aires, 1986 [2 ${ }^{\mathrm{a}}$ ed. corr. y aum. : Buenos Aires, Editorial Biblos, 1998].

GugliElmi, Nilda, Il Medioevo degli ultimi : emarginazione e marginalità nei secoli XI $X I V$, Roma, Citta nuova, 2001.

HARTUNG, Wolfgang, Die Spielleute : eine Randgruppe in der Gesellschaft des Mittelalters, Wiesbaden, F. Steiner, 1982. 
Hérésies et sociétés dans l'Europe pré-industrielle, $X I^{e}-X V I I I^{e}$ siècles, Communications et débats du Colloque de Royaumont présentés par Jacques LE GofF, Paris-La Haye, Mouton and Co, 1968.

Identidades marginales, Cristina DE LA PUENTE (ed.), Madrid, Consejo superior de investigaciones científicas, 2003.

L'Image de l'autre. Etrangers - Minoritaires - Marginaux, $\mathrm{XVI}^{\mathrm{e}}$ Congrès International des Sciences Historiques, Hélène AHRWEILER (éd.), 3 vol., Stuttgart, 1985.

JACOB, Robert, « Bannissement et rite de la langue tirée au Moyen Âge. Du lien des lois et de sa rupture », dans Annales : Histoire Sciences Sociales, 55 ${ }^{\mathrm{e}}$ année, ${ }^{\circ}$ 5, Paris, Armand Colin, sept.-oct. 2000, pp. 1039-1079.

Koopmans, Jelle, et VerhuYiCK, Paul, Sermon joyeux et truanderie (Villon-NemoUlespiègle), Amsterdam, Rodopi, 1987.

Koopmans, Jelle, Le théâtre des exclus au Moyen Âge : hérétiques, sorcières et marginaux, Paris, Imago, diff. PUF, 1997.

Linaje, familia y marginación en España : ss. XIII-XIX, ponencias presentadas en el Seminario Familia y Elite de poder en el reino de Murcia, siglos XV-XIX, Murcia, Universidad de Murcia, Departamento de Historia Moderna, Contemporanea y de América, 1992.

Malti-Douglas, Fedwa, Power, marginality, and the body in medieval Islam, Burlington (VT), Ashgate Variorum, 2001.

Marginalité, déviance, pauvreté en France, XIV $-X I X^{e}$ siècles, Centre de recherches d'histoire quantitative de l'Université de Caen, sous la dir. de Gabriel DÉSERT, préf. de Pierre CHAUnU, Caen, Annales de Normandie, $\mathrm{n}^{\circ} 13,1981$.

Mitre FernándeZ, Emilio, Fronterizos de Clio : marginados, disidentes y desplazados en la Edad Media, Granada, Universidad de Granada, 2003 (Collection : Biblioteca de Bolsillo, Collectanea).

Population et démographie au Moyen Âge, Actes du $118^{\mathrm{e}}$ Congrès national des sociétés historiques et scientifiques, Pau, 25-29 octobre 1993, Section Histoire médiévale et philologie, organisé par le Comité des travaux historiques et scientifiques, sous la dir. d'Olivier GUYOTJEANNIN, Paris, CTHS, 1995.

Randgruppen der spätmittelalterlichen Gesellschaft : ein Hand- und Studienbuch, hrsg. von Bernd-Ulrich HERGEMÖLLER, Warendorf, Fahlbusch, 1994.

ReXroth, Frank, Das Milieu der Nacht : Obrigkeit und Randgruppen im spätmittelalterlichen London, Göttingen, Vandenhoeck \& Ruprecht, 1999.

Richards, Jeffrey, Sex, Dissidence and Damnation: Minority Groups in the Middle Ages, London/New York, Routledge, 1990. 
ROBERT, Ulysse, Les signes d'infamie au Moyen Âge : juifs, sarrazins, hérétiques, lépreux, cagots, filles publiques, Paris, Honoré Champion, 1891.

SEKULES, Veronica, «Beauty and the Beast: Ridicule and Orthodoxy in Architectural Marginalia in Early Fourteenth-Century Lincolnshire ", Art History, 18, n 1, 1995, pp. 3752.

STARn, Randolph, Contrary Commonwealth: the Theme of Exile in Medieval and Renaissance Italy, Berkeley-Londres, University of California Press, 1982.

TAYLOR, Andrew, "Playing on the Margins: Bakhtin and the Smithfield Decretals", dans Bakhtin and Medieval Voices, éd. Thomas J. FARrell, University of Florida Press, 1995, pp. 17-37.

Théorie des marges littéraires, Actes de la journée d'étude du 8 octobre 2004, Université de Nantes, organisée par le Centre de recherches «Textes-Langages-Imaginaires », sous la direction de Philippe Forest et Michelle SzKILNIK, Nantes, C. Defaut, 2005 (Horizons comparatistes, nouvelle série).

Violència i marginació en la societat medieval, Pablo PÉREZ GARCÍA, Justo SERnA Alonso, Rafael NARBONA et al., València, Departament d'història medieval, Facultat de Geografia i Història, 1990.

ZAREMSKA, Hanna, Les bannis au Moyen Âge, trad. du polonais fr. par Thérèse Douchy, préface de Claude GAUVARD, Paris, Aubier, 1996. 